\title{
Trash to Supply Gas (TtSG) Project Overview
}

\author{
Paul E. Hintze ${ }^{1}$, Edgardo Santiago-Maldonado ${ }^{2}$ \\ NASA Kennedy Space Center, Kennedy Space Center, FL, 32899 \\ Michael J. Kulis ${ }^{3}$, John K. Lytle ${ }^{4}$ \\ NASA Glenn Research Center, Cleveland, OH, 44135 \\ John W. Fisher ${ }^{5}$ \\ NASA Ames Research Center, Moffett Field, CA 94035 \\ and \\ Helen Vaccaro ${ }^{6}$, Michael K. Ewert ${ }^{7}$, James L. Broyan ${ }^{8}$ \\ NASA Johnson Space Center, Houston, TX 77058
}

Technologies that reduce logistical needs are a key to long term space missions. Currently, trash and waste generated during a mission is carried during the entire roundtrip mission or stored inside a logistic module which is de-orbited into Earth's atmosphere for destruction. The goal of the Trash to Supply Gas (TtSG) project is to develop space technology alternatives for converting trash and other waste materials from human spaceflight into high-value products that might include propellants or power system fuels in addition to life support oxygen and water. In addition to producing a useful product from waste, TtSG will decrease the volume needed to store waste on long term space missions. This paper presents an overview of the TtSG technologies and future plans for the project.

\section{Nomenclature}

$\begin{array}{ll}\text { ACS } & =\text { advanced clothing system } \\ A E S & =\text { Advanced Exploration System } \\ A R C & =\text { Ames Research Center } \\ \mathrm{EVA} & =\text { extra-vehicular activity } \\ G R C & =\text { Glenn Research Center } \\ H M C & =\text { heat melt compactor } \\ K S C & =\text { Kennedy Space Center } \\ L E O & =\text { low Earth orbit } \\ L R R & =\text { Logistic Reduction and Repurposing } \\ \mathrm{LTL} & =\text { logistics-to-living } \\ T t S G & =\text { trash to supply gas }\end{array}$

\footnotetext{
${ }^{1}$ Chemist, Chemical Analysis Branch, Mail Code: NE-L6, NASA Kennedy Space Center, FL 32899.

${ }^{2}$ Chemical Engineer, Surface Systems Office, Mail Code: NE-S2, NASA Kennedy Space Center, FL 32899.

${ }^{3}$ Physical Scientist, Bioscience and Technology Branch, Mail Code: 110-3, NASA Glenn Research Center, Cleveland, OH 44135.

${ }^{4}$ Space Technology Office, Mail Code: 77-5, NASA Glenn Research Center, Cleveland, OH 44135.

${ }^{5}$ Lead Engineer, Exploration Life Support, NASA-Ames Research Center, Moffett Field, CA 94035.

${ }^{6}$ EP3/Energy Conversion Systems, NASA Johnson Space Center, 21012 NASA Parkway, Houston, TX, 77058.

${ }^{7}$ AES Logistics Reduction and Repurposing SE\&I Lead, Crew \& Thermal Systems Division, 21012 NASA Parkway, Houston, TX, 77058/Mail Stop EC2.

${ }^{8}$ AES Logistics Reduction and Repurposing Project Manager, Crew \& Thermal Systems Division, 21012 NASA Parkway, Houston, TX, 77058/Mail Stop EC3.
} 


\section{Introduction}

$\mathrm{T}$ here is no doubt that human space exploration is a very complex and challenging endeavor, and one of the complexities is the logistical needs and requirements to support a human mission. These logistical needs are costly, in both mass and volume, and are directly proportional to mission duration. As NASA prepares to plan human missions beyond Low Earth Orbit (LEO), revolutionary technologies for the reduction of logistics are needed. To address these needs, NASA has kicked off a Logistic Reduction and Repurposing (LRR) project ${ }^{1}$ under the Advanced Exploration Systems Program. The LRR project will enable a largely mission-independent cradle-tograve-to-cradle approach to minimize logistics contributions to total mission architecture mass. The goals of the Logistics project will be accomplished through four hardware tasks plus a strong systems engineering analysis and integration function. The four hardware oriented tasks are: (1) Conversion of logistical items to useable products via heat melt compactor (HMC) processing, (2) Conversion of trash to supply gas (TtSG) to make propellant from waste products, (3) Use of an Advanced Clothing System (ACS) to reduce mass, volume, and flammability, and (4) Use of logistics-to-living (LTL) to repurpose launch packaging containers. This paper will provide an overview of the TtSG technologies and an overview of the project objectives.

The overall goal of the Trash to Supply Gas (TtSG) task is to develop space technology alternatives for converting trash and other waste materials from human spaceflight into high-value products that might include propellants or power system fuels in addition to life support oxygen and water. This reuse of discarded materials is a critical component of closing the life support material loop. This task along with the LRR integrated analysis will determine the feasibility and benefits of this approach. The overall technical approach for TtSG is to adapt technology already developed by industry for terrestrial applications for use in space, and ensure that the results of this work are available for spin-off applications back on Earth.

Escaping from Earth's gravity well requires powerful and expensive propulsion systems. Maximum utilization of all materials launched is therefore essential. Leftover food packaging, food scraps, used clothing, tape, paper, and other trash materials can be converted from useless trash to high energy gases that can be used for energy production or propulsion in crewed spacecraft or rover vehicles. This capability would also address the concern of waste management during long-duration human missions by reducing the need to store trash for long time periods. In-situ processing of trash is an option to control waste, while maintaining a healthy habitable volume, during long-duration missions.

Current human spaceflight missions either carry trash during the entire round-trip mission or discard trash inside a logistic module which is de-orbited into Earth's atmosphere for destruction. Affordable human exploration beyond LEO will not include continuous logistic resupply from Earth and pressurized volume available for trash storage will be minimal. By converting waste materials that would be otherwise useless to propellants or fuels, the need to launch fuel to locations beyond Earth orbit is reduced. The additional cost of delivering mass to locations beyond LEO is even greater. Since typically over five kilograms per day of waste is produced for a crew of four, there is tremendous value to be gained by conversion of waste to fuels, as well as protecting the habitable environment.

Converting trash and waste into hydrocarbon fuels, water, and oxygen is a complex process requiring multiple processing steps. Feedstock may need to be conditioned by drying or grinding. The conditioned trash, mainly hydrocarbon based, is broken down into less complex shorter hydrocarbon molecular chains or into carbon oxides (mixture of carbon monoxide and carbon dioxide). Previous experience in this area by the principal investigators has provided background data and identified technical challenges which need to be overcome by the TtSG task ${ }^{2}$. Moderate temperature $\left(500^{\circ} \mathrm{C}-800^{\circ} \mathrm{C}\right)$ processes including pyrolysis, thermal oxidation, catalytic decomposition, and steam reforming have demonstrated production of mixtures of three carbon chains (C3) or higher hydrocarbons and a mixture of carbon oxides and hydrocarbons. These processes will be evaluated, first in laboratory settings, using standardized waste streams for comparison of estimated system mass and power consumption.

There are other possible products from the TtSG technologies. Some of the technologies produce carbon char which could be used in similar ways to activated carbon. It could also be a store of carbon that could be converted to carbon dioxide for plant growth when needed. Some of the technologies under investigation could be used to produce other hydrocarbons besides methane. For example, steam reforming is currently used in the chemical industry in combination with the Fisher Tropsch to make a variety of hydrocarbons.

Production of energy and fuels from waste products such as biomass is continually gaining popularity for terrestrial applications. There are challenges in adapting the terrestrial technologies for space application. The technologies must be miniaturized, as many terrestrial production plants are for converting landfill waste or biomass where there is a large continuous source of waste. Terrestrial technologies are also focusing on smaller production facilities that can operate at the source of the waste. The amount of astronaut interaction with the system and production of hazardous components are a concern. A system that requires a lot of human interaction or 
maintenance would be unacceptable. The production of hazardous or unpleasant substances must be avoided. A small quantity of hazardous components released in a closed spacecraft could have a much more drastic impact than in an open terrestrial environment. Many of the TtSG technologies produce components or residues that, although not toxic, smell very bad and would make adding trash to the system unpleasant.

\section{Technologies}

Each technology follows a similar path to convert trash into methane, with modifications based on the specifics of the individual technology. The general process flow is shown in Figure 1. The trash will go through an initial preparation step which includes shredding into smaller pieces and might include a drying step. Then the trash enters the processing step, in which it is converted to gas through one of the technologies listed in Table 1. Following this step, the gas will be cleaned and separated into individual components, as necessary. If the technology produces significant amounts of methane, the methane can be collected directly after the trash processing reactor. Otherwise, the product gas, a mixture of carbon oxides, will then be fed into a methanation or Sabatier reactor along with hydrogen, produced from an electrolyzer, to produce methane. Tars, ash or hazardous products will have to be separated from the trash processing reactor and the resulting gas stream, and is shown in the box labeled "other" in Figure 1.

Pyrolysis processes trash by heating in the absence of oxygen. The primary products are liquids, tars, char, and gasses. The mix of products can be adjusted by varying operating parameters and the use of catalysts that crack hydrocarbon liquids into gasses. The production of methane directly from pyrolysis is $1 \mathrm{lw}^{3}$, so pyrolysis likely would be coupled with another oxidation step to produce carbon dioxide that can be fed to the Sabatier reactor. The production of carbon char from pyrolysis is a potential advantage. The char can be reused as a filter material (activated carbon) or stored and converted to carbon dioxide for plant growth. In addition, since the production of methane from waste material is limited by the amount of hydrogen, the char provides a means of storing waste as carbon in a low volume if it is not desired to convert all carbon to methane.

Incineration and ozone oxidation ${ }^{4,5}$ both convert waste into carbon dioxide and water. The water is collected, sent to an electrolyzer and the resulting hydrogen is fed into a Sabatier reactor along with the carbon dioxide to produce methane. These processes have the advantage of being relatively straight forward and not requiring many steps. Since both methods seek to fully oxidize the waste, the amount of partially combusted, potentially toxic compounds is minimized. However, incineration produces hazardous products such as nitrogen oxides and sulfur oxides $\left(\mathrm{NO}_{\mathrm{x}}\right.$ and $\left.\mathrm{SO}_{\mathrm{x}}\right)$. In addition, incineration and ozone oxidation will require more power for the electrolyzer since neither method directly produces methane or hydrogen gas. Ozone oxidation operates at lower temperatures, near $125^{\circ} \mathrm{C}$, so it is less likely to produce $\mathrm{NO}_{\mathrm{x}}{ }^{5}$.

Gasification is the partial oxidation of the waste, converting solid material into a gas. In terrestrial applications, the product gas, called syn gas or producer gas, is used directly for heating, power generation or fuel production ${ }^{6}$. In this case, gasification is being investigated because it might directly produce significant amounts of methane and hydrogen, thus reducing the power and mass requirements for the electrolyzer and Sabatier reactor. Although gasification may produce methane directly, a Sabatier reactor will still be needed to maximize the amount of methane production ${ }^{2}$. Like pyrolysis, gasification can produce carbon char. Gasification produces tars and partially combusted hydrocarbons which will complicate the gas separation and cleanup step.

Steam reforming produces a mixture of hydrogen, carbon monoxide and carbon dioxide. It is the reaction of steam with hydrocarbons at elevated temperatures and pressures. The product gas is fed to a Sabatier or methanation reactor. The advantage of steam reforming is that it produces hydrogen directly and would require a smaller electrolyzer than needed for incineration or ozone oxidation.

Two low temperature catalytic methods, photocatalytic oxidation and wet air oxidation ${ }^{7}$, are being investigated. The methods can be used separately or in conjunction with each other. Photocatalytic oxidation converts waste into methane in the same way as incineration, but at much lower temperatures. It produces carbon dioxide and water which is fed to an electrolyzer and then a Sabatier reactor. Wet air oxidation uses a catalyst that can convert the waste to methane in a single reactor. The combination of photocatalyst and wet air oxidation may increase the rate of reaction. In addition, GRC is investigating the use of solar collectors to provide heat to the wet air oxidation reactor. 


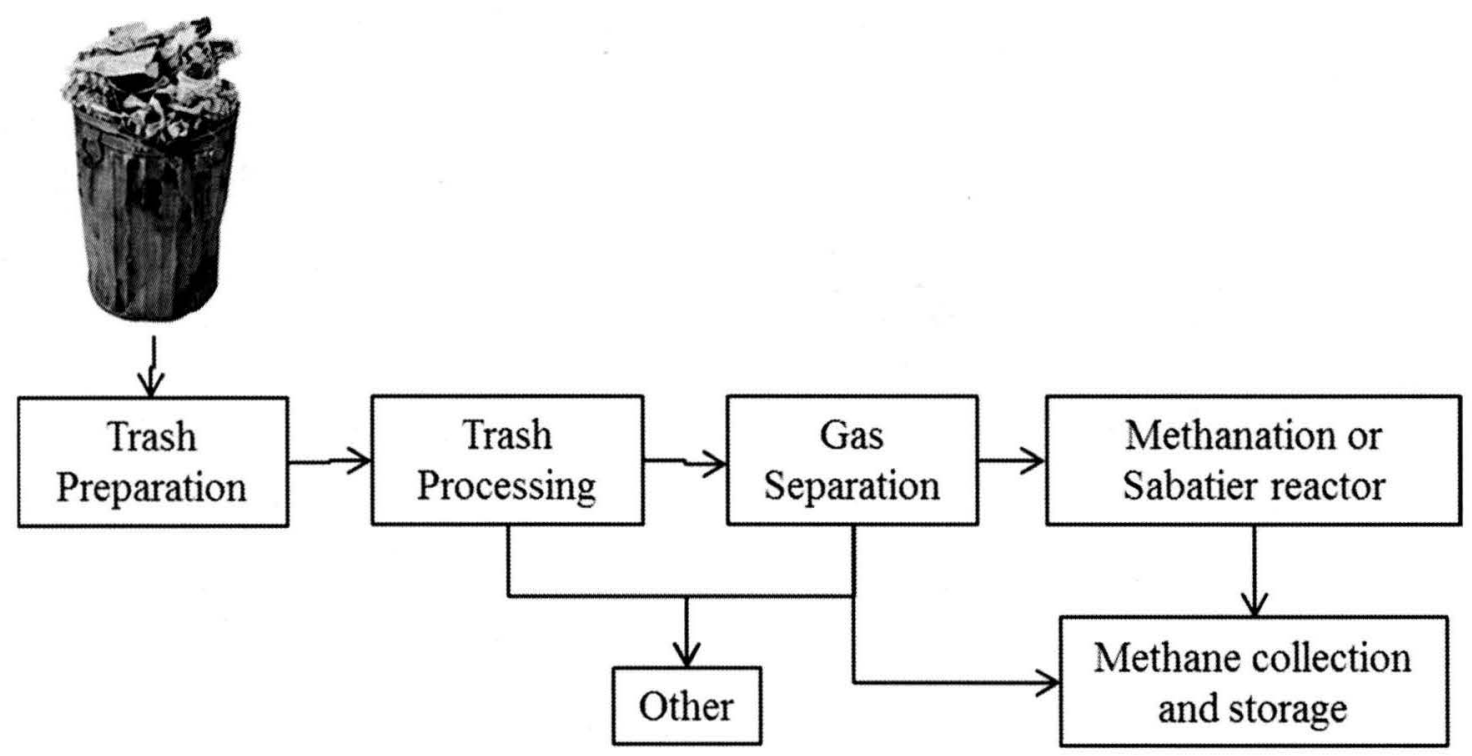

Figure 1. General process flow for TtSG technologies.

Table 1. Trash Processing Technologies

\begin{tabular}{|c|c|c|c|c|c|c|}
\hline General Technology & Subtypes & Process Options & Temp. $\left({ }^{\circ} \mathrm{C}\right)$ & \begin{tabular}{|c|} 
Pressure \\
(atm)
\end{tabular} & $\begin{array}{l}\text { End Products/ } \\
\text { By-products }\end{array}$ & Past Work \\
\hline \multirow[t]{3}{*}{$\begin{array}{l}\text { THERMAL } \\
\text { TREATMENT }\end{array}$} & $\begin{array}{l}\text { Pyrolysis (Thermal } \\
\text { decomposition) }\end{array}$ & Fast pyrolysis & $400-650^{\circ} \mathrm{C}$ & $\sim 1 \mathrm{~atm}$ & $\begin{array}{l}\text { Liquids, tars, } \\
\text { char, gases }\end{array}$ & ARC; KSC \\
\hline & Gasification & $\begin{array}{l}\text { Direct/ Partial } \\
\text { oxidation }\end{array}$ & $400-800^{\circ} \mathrm{C}$ & $\sim 1 \mathrm{~atm}$ & $\begin{array}{l}\text { Synthesis gas } \\
\left(\mathrm{CO}, \mathrm{CO}_{2}, \mathrm{H}_{2},\right. \\
\left.\mathrm{CH}_{4}, \mathrm{H}_{2} \mathrm{O}\right)\end{array}$ & KSC \\
\hline & Incineration & $\begin{array}{l}\text { Incineration mass } \\
\text { burn/auger feed }\end{array}$ & $\begin{array}{l}300-1000 \\
{ }^{\circ} \mathrm{C}\end{array}$ & $\sim 1 \mathrm{~atm}$ & $\mathrm{CO}_{2}, \mathrm{H}_{2} \mathrm{O}$, ash & KSC; ARC \\
\hline \multirow{2}{*}{$\begin{array}{l}\text { CHEMICAL } \\
\text { OXIDATION }\end{array}$} & Ozone Oxidation & Wet ozonation & $125^{\circ} \mathrm{C}$ & $5 \mathrm{~atm}$ & $\mathrm{CO}_{2}, \mathrm{H}_{2} \mathrm{O}$ & ARC \\
\hline & Steam Reforming & Steam Reforming & $400-600$ & $220 \mathrm{~atm}$ & $\mathrm{CO}, \mathrm{CO}_{2}, \mathrm{H}_{2}$ & GRC \\
\hline \multirow[t]{2}{*}{$\begin{array}{l}\text { CATALYTIC } \\
\text { DECOMPOSITION }\end{array}$} & \multirow{2}{*}{$\begin{array}{l}\text { Low Temperature } \\
\text { Catalytic } \\
\text { Decomposition }\end{array}$} & $\begin{array}{l}\text { Photocatlytic } \\
\text { oxidation }\end{array}$ & $<100$ & $\sim 1$ & $\mathrm{CO}_{2}, \mathrm{H}_{2} \mathrm{O}$ & GRC \\
\hline & & Wet air oxidation & $150-325$ & $20-200$ & $\begin{array}{l}\mathrm{CH}_{4}, \mathrm{CO}_{2}, \mathrm{CO}, \\
\mathrm{H}_{2}\end{array}$ & GRC \\
\hline
\end{tabular}

\section{Waste Composition}

As part of the LRR project, a waste model showing the waste generated during a one year space mission was developed ${ }^{1}$. The estimated total amount of waste generated by four crew members during a one year mission is $1900 \mathrm{~kg}$ wet and $1150 \mathrm{~kg}$ dry mass. This amount of waste can be converted to approximately $1500 \mathrm{~kg}$ of methane. This total includes wastes that are thought to be appropriate for TtSG and does not include other wastes, such as metals, that cannot be processed by TtSG technologies. The major waste sources include food packaging and left over food, human wastes, hygiene items and clothing. On a dry mass basis, food packaging, clothing and maximum absorbent garments or MAGs, (used during EVAs) are the largest contributors to the waste stream. The trash is collected in small bags, called footballs, which contain, for example, garbage from a meal that is placed in a bag and wrapped with duct tape ${ }^{8}$.

The waste will contain many components including polymers, natural fibers such as cotton and salts. The food packaging is a laminate material that contains polyethylene, nylon, polyethylene terephthalate, and aluminum. The 
clothing consists of cotton and the MAGs are diapers that contain multiple polymers as well as sodium polyacrylate as the absorbent.

Because of the complex waste stream, a set of waste simulants was created for use in initial stages of TtSG technology development. The waste simulants consist of medium and high fidelity simulants of the major components of the waste stream. The three medium fidelity waste simulants are a food packaging simulant, cotton cloth, and diaper. The cotton cloth and diaper are run by themselves, while the food packaging simulant is a combination of polymers determined from analysis of actual food packaging. The medium fidelity waste simulants and composition of the food packaging simulant are given in Table 2 . The medium fidelity simulants do not contain any water.

Table 2. Medium fidelity waste simulants.

\begin{tabular}{ccc}
\hline Waste & Simulant & Mass \% \\
\hline MAGs & Commercially available diaper & $100 \%$ \\
\hline \multirow{3}{*}{ Food Packaging } & Polyethylene & $52 \%$ \\
& Polyethylene terephthalate & $14 \%$ \\
& Nylon & $13 \%$ \\
\hline Cotton Towels & Aluminum foil & $22 \%$ \\
\hline
\end{tabular}

The high fidelity waste simulants consists of the medium fidelity simulants to which food or simulated human wastes have been added. Compositions of the simulants are given in Tables $3-6$. Table 3 gives the mass percentages for the major components of the high fidelity simulants. The detailed composition of each component is referenced and given in the other tables. The food packaging to food ratio was taken from the HMC waste simulant model. Table 4 gives the components of the food simulant, which was also adapted from the HMC waste simulant. The number of components was reduced, but the water content was kept the same ( $81 \%$ water). The mass ratio of feces and urine to MAGs was taken from the Baseline Values and Assumptions Document ${ }^{9}$ estimates on extravehicular activity for a Lunar outpost mission. Table 5 gives the formula for simulated feces ${ }^{10}$ and Table 6 gives the formula for simulated urine ${ }^{11}$.

Table 3. Composition of high fidelity simulants.

\begin{tabular}{ccc}
\hline Waste & Simulant & Mass \% \\
\hline \multirow{2}{*}{ Food } & Packaging (Table 2) & $58 \%$ \\
& Food (Table 4) & $42 \%$ \\
\multirow{3}{*}{ MAGs } & Diapers & $30 \%$ \\
& Simulated feces (Table 5) & $1 \%$ \\
& Simulated urine (Table 6) & $69 \%$ \\
\hline
\end{tabular}

Table 4. Composition of food simulant.

\begin{tabular}{cc}
\hline Component & Mass \% \\
\hline Juice & $41 \%$ \\
Dried apricot & $11 \%$ \\
Tortilla & $21 \%$ \\
hot dog & $27 \%$ \\
\hline
\end{tabular}

Table 5. Composition of simulated feces.

\begin{tabular}{lc}
\hline Component & Mass \% \\
\hline Cellulose & $6 \%$ \\
Polyethylene glycol (PEG) & $3 \%$ \\
Peanut Oil & $11 \%$ \\
Miso & $17 \%$ \\
Potassium chloride $(\mathrm{KCl})$ & $2 \%$ \\
Calcium chloride $(\mathrm{CaCl} 2)$ & $1 \%$ \\
Water & $60 \%$ \\
\hline
\end{tabular}


Table 6. Composition of simulated urine.

\begin{tabular}{cc}
\hline Component & Concentration $(\mathbf{g} / \mathbf{L})$ \\
\hline Urea & 5.20 \\
Taurine & 0.06 \\
Creatinine & 0.52 \\
Histidine & 0.10 \\
Glutamic acid & 0.17 \\
Glucose & 0.26 \\
\hline Ammonium citrate & 1.23 \\
\hline Ammonium formate & 0.15 \\
\hline Ammonium oxalate & 0.07 \\
monohydrate & 2.31 \\
Sodium chloride & 0.55 \\
Magnesium chloride & 0.22 \\
hexahydrate & 0.05 \\
Potassium bicarbonate & 0.11 \\
Potassium carbonate & 0.54 \\
Potassium monobasic phosphate & 0.74 \\
Potassium chloride & 0.02 \\
\hline Potassium sulfate & 0.41 \\
\hline Calcium chloride & \\
Sodium sulfate & \\
\hline
\end{tabular}

\section{Conclusion}

As the TtSG project progresses, one or two technologies from this group will be selected for future development. The down selection is scheduled to occur in 2013. The factors used to evaluate the technologies include trash processing rate, conversion efficiency, production of hazardous compounds, power, and mass requirements for the trash processing technology and the associated electrolyzer, gas separation, and Sabatier reactor systems. After down selection, a prototype unit for conversion of trash to methane will be demonstrated in 2014.

\section{Acknowledgments}

The authors would like to thank all the contributors to the TtSG task from NASA Ames Research Center, Glenn Research Center, Johnson Space Center and Kennedy Space Center. The AES LRR project is funded by the NASA Headquarters Advanced Exploration Systems Division.

\section{References}

${ }^{1}$ Broyan Jr., J.L. and M.K. Ewert. "Logistics Reduction and Repurposing Beyond Low Earth Orbit," 42nd International Conference on Environmental SystemsSan Diego, CA, 2012.

${ }^{2}$ Santiago-Maldonado, E., et al. "Creating Methane from Plastic: Recycling at a Lunar Outpost," 48th AIAA Aerospace Sciences Meeting Including the New Horizons Forum and Aerospace Expostion,AIAA 20101551, Orlando, FL, 2010.

${ }^{3}$ Serio, M.A., et al. "Methane Production from Pyrolysis of Mixed Solid Wastes," 42nd International Conference on Environmental Systems,AIAA 2012-3567, San Diego, CA, 2012.

${ }^{4}$ Nabity, J.A., et al. "Low Temperature Ozone Oxidation of Solid Waste Streams," 40th International Conference on Environmental Systems,AIAA 2010-6034, Barcelona, 2010.

${ }^{5}$ Nabity, J.A., et al. "A Pilot Scale System for Low Temperature Solid Waste Oxidation and Recovery of Water," International Conference on Environmental Systems,2009-01-2365, Savannah, GA, 2009.

${ }^{6}$ Balat, M., et al., "Main routes for the thermo-conversion of biomass into fuels and chemicals. Part 2: Gasification systems." Energy Conversion and Management, 50, 12, 2009: p. 3158-3168.

${ }^{7}$ Kulis, M.J., K.J. Guerrero-Medina, and A.F. Hepp. "Development of a Catalytic Wet Air Oxidation Method to Produce Feedstock Gases from Waste Polymers," 9th Annual International Energy Conversion Engineering Conference, AIAA 2011-5739, AIAA, San Diego, CA, 2011.

6

American Institute of Aeronautics and Astronautics 
${ }^{8}$ Strayer, R.F., et al. "Characterization of Volume F trash from four recent STS missions: weights, categorization, water content," 41st International Conference on Environmental Systems, AIAA-2011-5126, Portland, OR, 2011.

${ }^{9}$ Duffield, B.E., Exploration Life Support Baseline Values and Assumptions Document. 2010, NASA Johnson Space Center.

${ }^{10}$ Wignarajah, K., et al. "Simulated Human Feces for Testing Human Waste Processing Technologies in Space Systems," International Conference on Environemental Systems, 2006-01-2180, S. International, Norfolk, VA, 2006.

${ }^{11}$ Verostko, C., C. Carrier, and B. Finger. "Ersatz Wastewater Formulations for Testing Water Recovery Systems," International Conference on Environmental Systems, 2004-07-19, S. International, Colorado Springs, CO, 2004. 

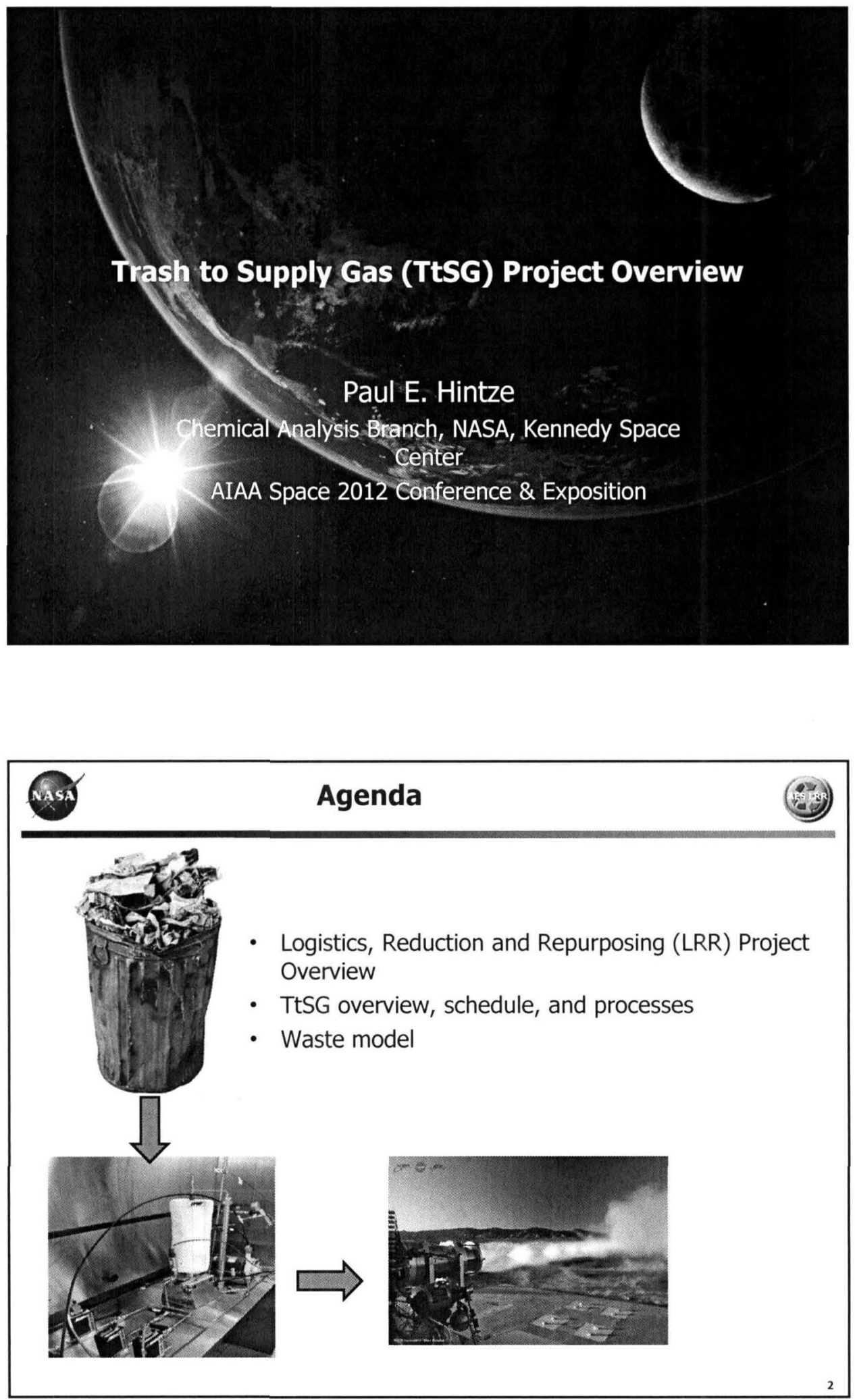


\section{LRR Overview}

- Summary

- Logistics Reduction and Repurposing (LRR) will utilize a cradle-to-grave approach to logistics to reduce total mission logistical up mass.

- LRR will demonstrate efficient methods to repurpose hardware originally designed for other uses, reduce packaging volume, and using common system elements for multiple mission applications.

- Minimize intrinsic logistics mass.

- Direct logistics component repurposing for on-orbit outfitting.

- Compact and process logistics to useful components and products.

- Enable long term stable storage and disposal

- Enable logistics sharing between vehicles in different mission phases

- Goals: new capabilities and exploration affordability

- Reuse and repurposing will reduce initial up mass and volume because it will reduce the number of dedicated crew outfitting items.

- Compacted/processed logistical material available for radiation shielding, water, or propellant.

- Enable more hygienic crew environments through waste stabilization.

- Increase habitable volume over mission duration through compaction.

- Reduced mass will reduce vehicle cost.

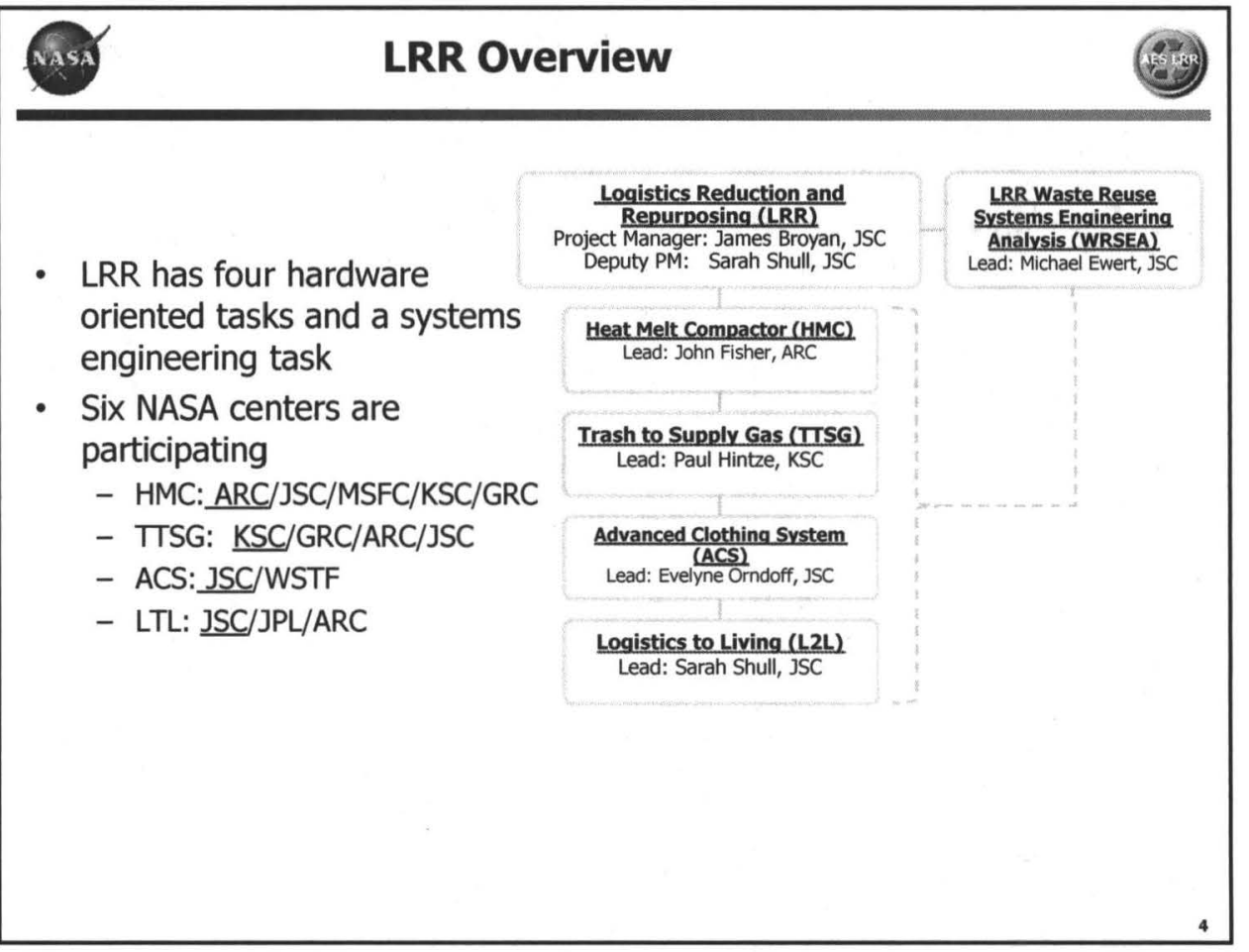




\section{TtSG Overview}

- What is it?

- A series of space technology alternatives for converting trash and other waste materials from human spaceflight into high-value products that might include propellants, power system fuels or oxygen and water for life support.

- Products: This activity investigates promising lower TRL technologies that process waste (trash \& human waste) all the way to gases which can be reused, thus saving launch mass.

- Methane, hydrogen and oxygen are all candidates for use in propulsion. Hydrogen and oxygen can also be reused for ECLSS.

- Systems Engineering Analysis task will guide the testing and selection of these technologies, which will come primarily from SBIR and other past work.

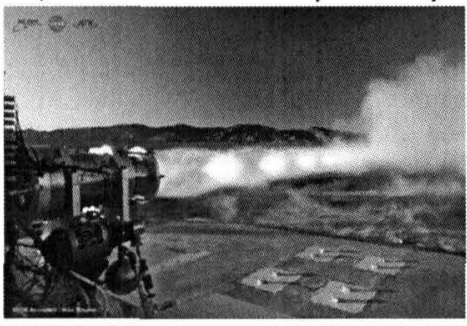

\section{TtSG Overview}

- Why TtSG?

- Reduce volume of trash - Current human spaceflight missions either carry trash during the entire round-trip mission or discard trash inside a logistic module which is de-orbited into Earth's atmosphere for destruction.

- Produce something useful from a waste product

- Challenges

- Miniaturization

- Operation with minimal human interaction

- Do not produce hazards

- Gas cleaning and purification

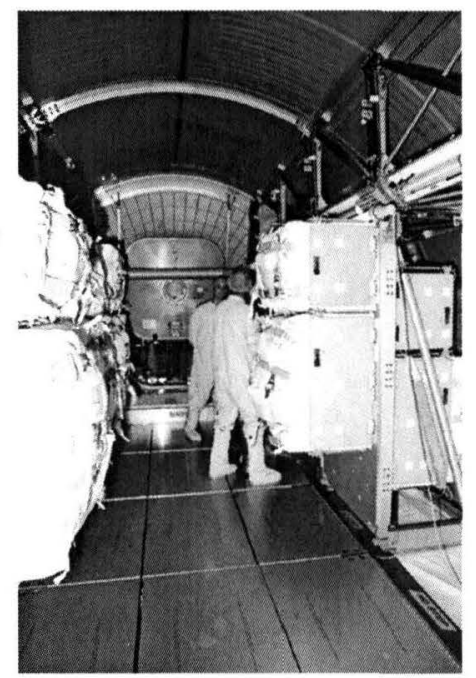

KSC-01PP-0726: Workers in the Space Station Processing Facility are removing contents from the Multi-Purpose Logistics Module (MPLM) Leonardo to begin removing the contents after STS-102. The MPLM brought back nearly a ton of trash and excess equipment from the Space Station. 6 


\section{TtSG Schedule}

- FY12:

- Testing existing prototypes

- Efficiency analysis

- Waste characterization analysis

- FY13:

- Mixed trash testing

- Down-selection to two processes for breadboard design

- FY14:

- Complete breadboard design testing

- Upgrade analysis

- FY15:

- Build upgraded prototype

- Provide mission architecture recommendations

- FY17:

- ISS flight project design complete

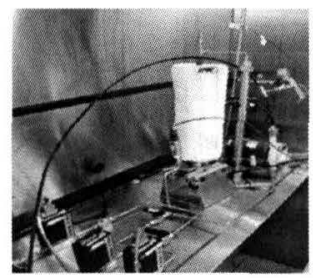

Thermal oxidation reactor at KSC

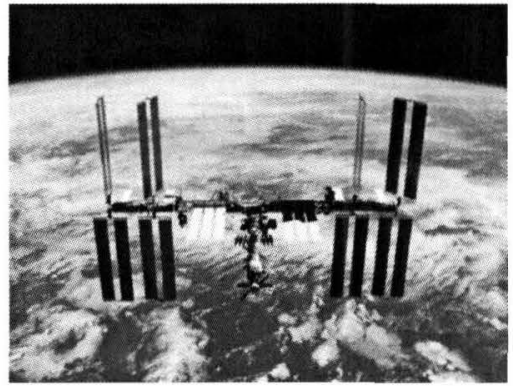

\section{TtSG Processes}

- KSC, GRC, ARC have hardware that they are testing

- All processes have a 3-4 TRL

- Pyrolysis

- Decomposition of waste materials with heat in the absence of oxygen

- Gasification

- Decomposition of waste materials with heat in the presence of oxygen and/or steam

- Incineration

- Decomposition of waste materials with combustion

- Steam Reforming

- Decomposition of waste materials with heat in the presence of steam

- Catalytic Decomposition- Low Temperature Decomposition of waste materials in the presence of a catalyst

- Wet air oxidation

- Photocatalytic oxidation

- Ozone Oxidation

- Decomposition of waste materials with heat in the presence of ozone

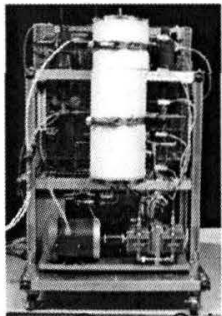

Ozone Oxidation System (ARC)

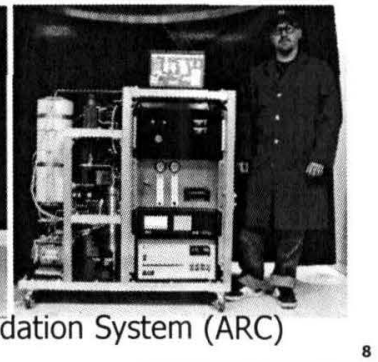




\section{TtSG Processes}

- Wood gas car, Biofuel power generation
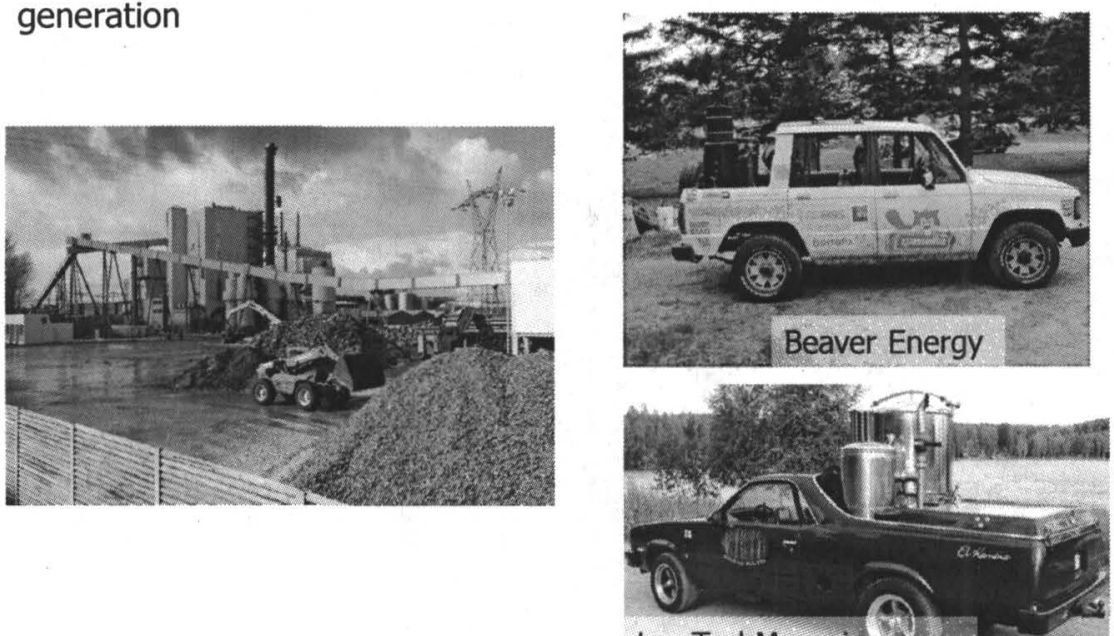

LowTechMagazine com

\section{TtSG General Systems Analysis}

- No power or volume trades completed

\section{- Assumptions}

- Crew of 4 for 360 days

- Waste types: Human Waste, Packaging, Adhered Food, Uneaten Food, MAGS, Gray Tape, Paper, Clothing, Towels, Washcloths

- Waste quantity: $1144.8 \mathrm{~kg}$ dry mass, 771.8 kg water; Crew metabolism 4200 $\mathrm{kg}$

- Additional $\mathrm{O} 2$ and $\mathrm{H} 2 \mathrm{O}$ added to processes in analysis to equate $\mathrm{CH} 4$ output - On a dry mass basis, complete conversion is hydrogen limited

- Technologies produce $1500 \mathrm{~kg}$ of methane

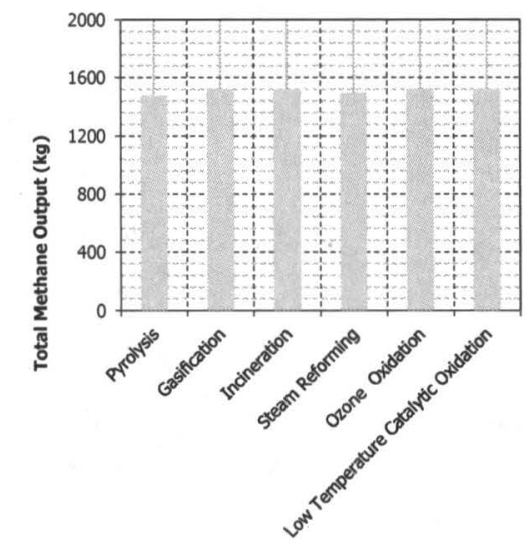

- Technologies produce $1900-2300 \mathrm{~kg}$ of oxygen

- Integrated systems require $500-1000$ $\mathrm{kg}$ of water as extra payload 

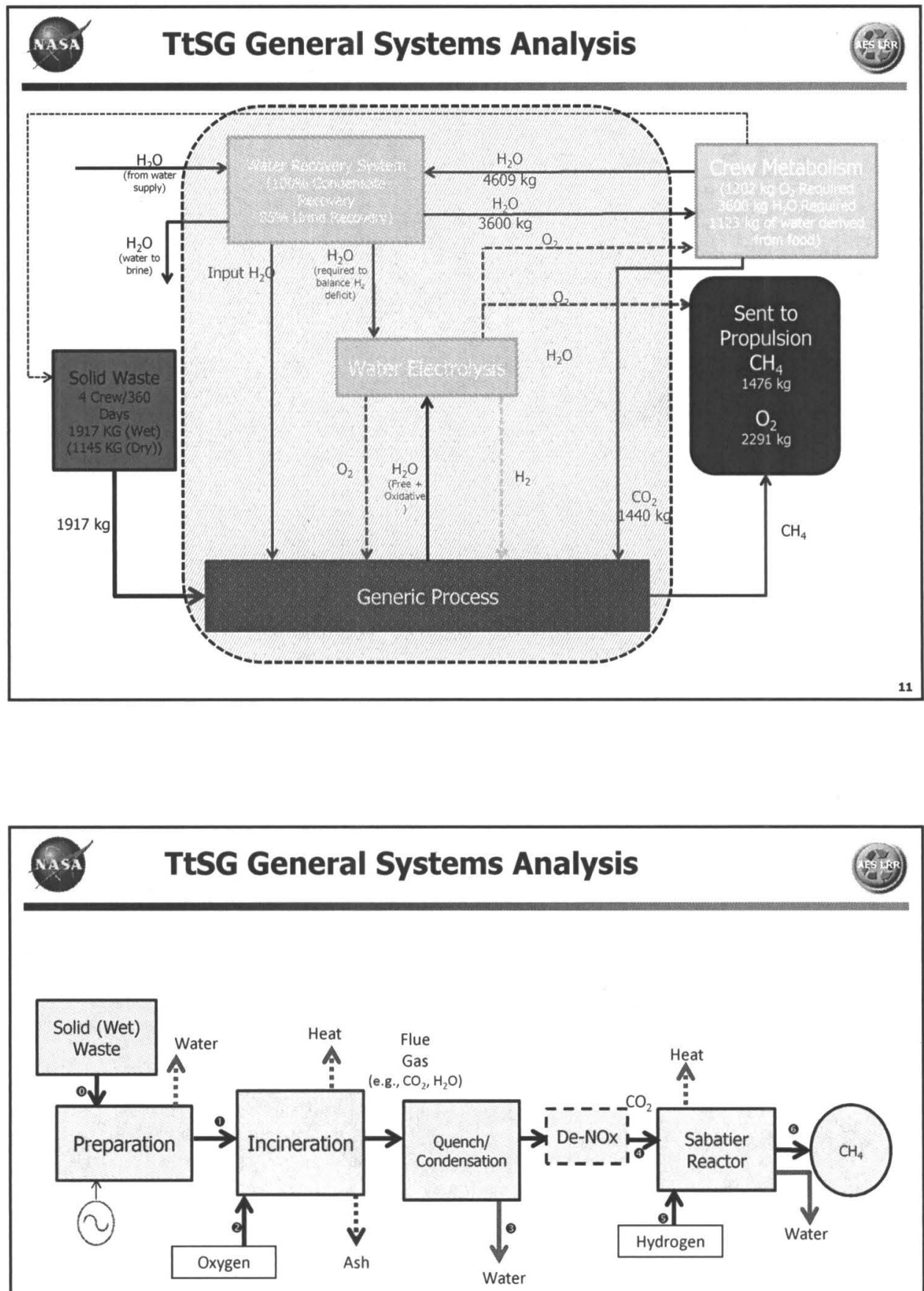


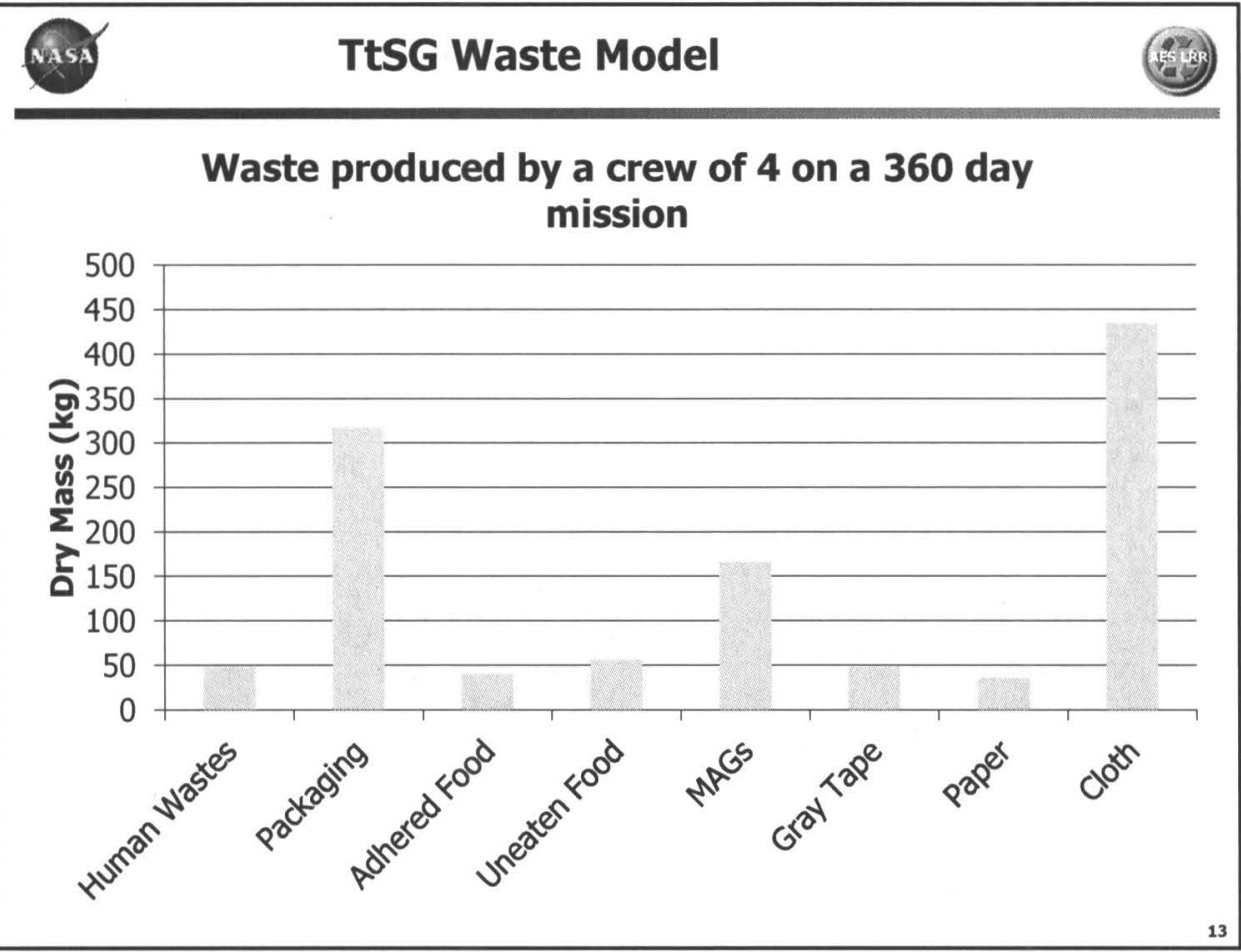

- Waste Simulants

- Cloth, food packaging and MAGs (Maximum Absorbent Garments) were selected as initial simulants to test technologies

- Future simulants will include food and simulated human wastes

- Washcloth

- Cotton is predominantly cellulose; $44 \%$ Carbon, $6 \%$ Hydrogen, $50 \%$ Oxygen by mass

- Diaper

- Diaper contains multiple polymers and materials including the sorbent, Velcro and elastic. No elemental estimation made at this point

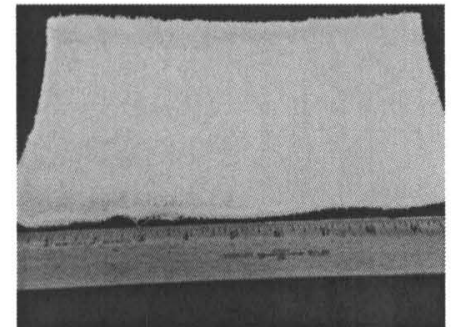

Washcloth

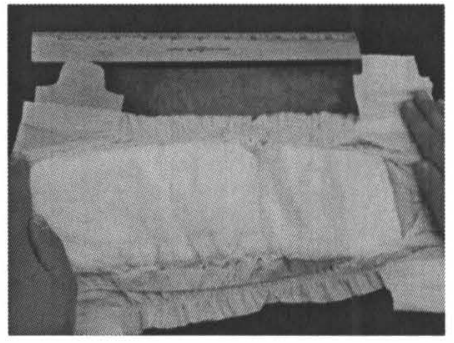

Diaper 


\section{TtSG Waste Model}

- Food Packaging Simulant (FPS)

- $22 \%$ aluminum foil

- $14 \%$ Polyethylene terephthalate (from water bottle) 63\% Carbon, $4 \%$ Hydrogen, $33 \%$ Oxygen by mass

- $13 \%$ Nylon $69 \%$ Carbon, $6 \%$ Hydrogen, $13 \%$ Oxygen, $12 \%$ Nitrogen by mass

- $51 \%$ PE; $86 \%$ Carbon, $14 \%$ Hydrogen by mass
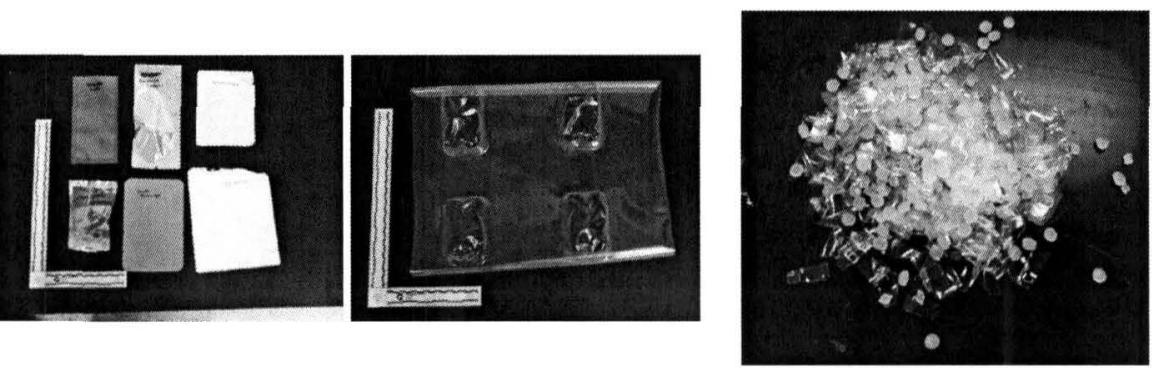

Food Packaging

Food Packaging Simulant

\section{TtSG Contacts}

\begin{tabular}{|c|c|c|c|}
\hline $\begin{array}{l}\text { Paul Hintze } \\
\text { Edgardo Santiago- } \\
\text { Maldonado }\end{array}$ & $\begin{array}{l}\text { NASA Kennedy Space } \\
\text { Center }\end{array}$ & $\begin{array}{l}\text { TtSG Lead, Gasification, } \\
\text { Incineration }\end{array}$ & Paul.E.Hintze@nasa.gov \\
\hline $\begin{array}{l}\text { John Lytle } \\
\text { Mike Kulis }\end{array}$ & $\begin{array}{l}\text { NASA Glenn Research } \\
\text { Center }\end{array}$ & $\begin{array}{l}\text { Catalytic wet air } \\
\text { oxidation, photocatalytic } \\
\text { oxidation }\end{array}$ & John.K.Lytle@nasa.gov \\
\hline $\begin{array}{l}\text { John Fisher } \\
\text { Jeffrey M. Lee }\end{array}$ & $\begin{array}{l}\text { NASA Ames Research } \\
\text { Center }\end{array}$ & Ozone Oxidation & John.W.Fisher@nasa.gov \\
\hline James L. Broyan & $\begin{array}{l}\text { NASA Johnson Space } \\
\text { Center }\end{array}$ & LRR lead & James.L.Broyan@nasa.gov \\
\hline Michael K. Ewert & $\begin{array}{l}\text { NASA Johnson Space } \\
\text { Center }\end{array}$ & $\begin{array}{l}\text { Systems Engineering } \\
\text { Lead }\end{array}$ & Michael.K.Ewert@nasa.gov \\
\hline Helen Vaccaro & $\begin{array}{l}\text { NASA Johnson Space } \\
\text { Center }\end{array}$ & Sabatier reactor & Helen.Vaccaro-1@nasa.gov \\
\hline
\end{tabular}

